\title{
6
}

\section{A APOTEOSE ERÓTICA DE CLAUDIO RODRÍGUEZ FER}

\section{THE EROTIC APOTHEOSIS OF CLAUDIO RODRÍGUEZ FER}

\author{
Leilson Assad de Souza Filho ${ }^{1}$ \\ Universidade Federal do Amazonas \\ Saturnino Valladares ${ }^{2}$ \\ Universidade Federal do Amazonas
}

Resumo: O objetivo deste artigo é apresentar "Somente a apoteose", primeira parte da obra Uma temporada no paraíso do poeta galego Claudio Rodríguez Fer. Com este propósito mostrarei alguns poemas nos que predominam a temática erótica, o compromisso social e a utopia libertária. Além de A dupla chama de Octavio Paz, usarei como embasamento teórico os estudos de especialistas neste autor, como Saturnino Valladares, Olga Novo e Natalia Regueiro. De grande riqueza temática, os micropoemas de "Somente a apoteose" mantêm as características que referenciam o poeta como pioneiro no tratamento do erotismo na literatura galega.

Palavras-chave: Uma temporada no paraíso; Claudio Rodríguez Fer; Literatura erótica.

${ }^{1}$ professorleilsonassad@yahoo.com

2 saturninovalladares@gmail.com 
Abstract: The purpose of this article is to present "Only the apotheosis", the first part of the work Uma temporada no paraíso of the Galician poet Claudio Rodríguez Fer. For this purpose, I will show some poems in which the erotic theme, social commitment, and libertarian utopia predominate. In addition to A double call Octavio Paz, I will use as a theoretical basis the studies of specialists in this author, such as Saturnino Valladares, Olga Novo, and Natalia Regueiro. Of great thematic richness, the micro poems of "Somente a apoteose" maintain the characteristics that refer to the poet as a pioneer in the treatment of eroticism in Galician literature.

Keywords: Uma temporada no paraíso; Claudio Rodríguez Fer; Erotic literature.

\section{CLAUDIO RODRÍGUEZ FER - UMA TEMPORADA NO PARAÍSO}

Claudio Rodríguez Fer nasceu na cidade de Lugo em 1956, é poeta, dramaturgo, narrador e ensaísta de vanguarda. Escritor de uma trintena de obras, este pioneiro no tratamento do erotismo da literatura galega é considerado talvez o último poeta popular da língua em questão, pois, conforme Saturnino Valladares, é "respeitado por essa minoria a que dedicava Juan Ramón Jiménez seus livros de poemas, querido pelo povo e por todos admirado" (VALLADARES, 2014, p. 3). Ele tem dedicado vários livros ao erotismo: Vulva - que reúne seus cinco primeiros poemários -, A unha muller desconhecida, Viaxes a ti, e o nosso objeto de estudo, Unha tempada no paraíso. Sua obra está traduzida a vários idiomas, como espanhol, catalão, francês, italiano, romanés, inglês, alemão, bretão, grego, russo, árabe, incluindo a tradução a língua portuguesa realizada em 2019 por Saturnino Valladares e lançada pela editora Valer. Atualmente, ocupa o cargo de diretor da Cátedra José Ángel Valente de Poesia e Estética e da revista universitária Moenia, ambas da Universidade de Santiago de Compostela e administra os cadernos interculturais Unión libre.

O poeta começou a escrever poesia aos oito anos por influência de seus pais, já que estes tiveram fundamental importância em sua formação educacional, ética e política, pois conforme afirma Natalia Regueiro: 
Ambos os proxenitores foron fundamentais na educación do futuro escritor, xa que se criará e cursará o ensino primário na escola da nai, ubicada na Explanada da Estación e formarase ética e politicamente baixo a influência humanística e progressista do pai (REGUEIRO, 1998, p. 16). ${ }^{3}$

Desde seu primeiro livro, Poemas de amor sem morte (1979), até a obra Uma temporada no paraíso (2010), são perceptíveis os aportes vanguardistas e as conexões estabelecidas com as vanguardas, sendo o surrealismo "a vanguarda que mais pegadas deixou na sua poesia" (REGUEIRO, 1998, p. 44).

Uma temporada no paraíso aporta elementos recorrentes na trajetória poética claudiana, como a natureza de Galícia e o celtismo, pois "na sua poesia, Galicia aparece como paisaxe e como comunidade em loita desde os seus primeiros livros" (REGUEIRO, 1998, p. 14).

Este poeta faz um convite através de Uma temporada no paraíso a que conheçamos este paraíso utópico terrestre, lugar onde os prazeres carnais e múltiplos se realizem, “onde o encontro amoroso desconhecerá seu fim e toda a beleza do mundo cabe numa mirada" (VALLADARES, 2014, p. 9). Sua lírica questiona as formas tradicionais de imposição de sentimentos, sugerindo através do amor o autoconhecimento, o aprendizado e a descoberta de que "a vida é mais formosa no paraíso" (VALLADARES, 2014, p. 3).

A obra é uma réplica a Uma temporada no inferno de Arthur Rimbaud, pois o autor acredita que o paraíso na terra seja possível. Em seus poemas, ele expressa seus ideais libertários, sua ética e seu compromisso social pela justiça no mundo, e entrega-nos o sonho de que “após conhecer este paraíso poético, humanístico e vital [...], tudo no inferno se volta mais purgatório" (VALLADARES, 2014, p. 3). Tema recorrente na trajetória poética do autor, a viagem imaginária a esse paraíso utópico, transcendental e cognoscitivo permite a descoberta de outros mundos, em outros corpos livres que

\footnotetext{
${ }^{3}$ As citações retiradas de obras em língua galega não serão traduzidas, pois entendemos que não apresentarão dificuldade devida à proximidade com a língua portuguesa.
} 
reivindicam a liberdade plena e a reinvenção do amor assentada em um nomadismo ancestral. Essa viagem também se revela como um deslumbrante convite ao interior dos corpos, passando pelos pelos labirintos da carne, onde adquire-se o conhecimento por meio do prazer.

Outro ponto importante a respeito da utopia libertária defendida pelo poeta são alguns questionamentos feitos em relação a posição que a mulher ocupa na sociedade, seus padrões de comportamento e as imposições feitas pelo tradicionalismo convencional, o que Natalia Regueiro (1998) ratifica dizendo:

a base familiar e o rol tradicional do sexo/gênero em perfeita conexão com os postulados feministas e oferece uma visão da mulher absolutamente livre e independente, que subverte os padrões genéricos e que faz do amor uma revolução, e da vida uma utopia (REGUEIRO, 1998, p. 54).

É importante reforçar que a temática erótica de Rodríguez Fer parte de uma perspectiva determinada, que para Olga Novo (1996) está:

Eroticamente perfilada pelo feito de se tratar de uma perspectiva masculina e heterossexual. E ainda que o feminino - e por tanto também o feminino lésbico - tenha uma especial relevância, não há que esquecer que se apresentará sempre desde uma ótica não feminina e não homossexual. (NOVO, 1996, p. 7)

Claudio Rodríguez Fer é um dos pioneiros na utilização do erotismo na literatura galega e, conforme ele próprio indica, sua poesia é ele mesmo: uma forma de conhecimento, uma luta contra as limitações, o espaço da reflexão, uma busca pela extralimitação, e um convite a romper contra toda forma de opressão no mundo.

1 O PARAÍSO NA TERRA - EROTISMO

A manifestação do erotismo para Claudio Rodríguez Fer se apresenta de forma não convencional e, geralmente, desorganiza a estrutura tradicional 
familiar, pois em vários momentos se desenvolve através da representação de três elementos: o amor, amante e o amado. Estes três oferecem através da união dos corpos o equilíbrio entre o amante, as amadas e uma perspectiva cosmogônica. Esta subversão dos padrões tradicionais dialoga com o que Natalia Regueiro apresenta dizendo que "o paraíso terrestre tinha que ser Lilith, Adão e Eva" (REGUEIRO, 1998, p. 54). Podemos observar tais características nos poemas “Um”, "Graças" e “Núcleo":

\section{UM}

Às vezes

para ser um

é preciso ser três.

\section{NÚCLEO}

São núcleo

de três células.

São célula

de três núcleos.

\section{GRAÇAS}

Oferecer as três deusas

a maça indivisível

e partilhada da macieira

da beleza.

Nesta parte o autor nos permite sonhar a respeito de um lugar utópico sobre a terra, um paraíso antibíblico onde para as pessoas "não há queda senão vida, não há falta senão amor, não há culpa senão prazer, como não há deus senão a apoteose da matéria" (NOVO, 2010, p. 13).

“Um” faz um convite a realização do prazer físico, a desfrutação do gozo em um movimento continuo de extralimitação, mas em três corpos, e propõe também o descobrimento da infinidade de prazeres cujo toque pode oferecer o vislumbre de novos caminhos. Essa subversão dos padrões tradicionais em busca do autodescobrimento não aparece somente em sua poesia, mas também 
em sua narrativa, como assinala Natalia Regueiro (1998), que afirma que o autor:

Subverte a fórmula tradicional da parella como patrón de relación amorosa, como sucede no conxunto de relatos titulados 'Tres' (...), en torno a um triángulo amoroso de perfecto equilíbrio no que os protagonistas gozan dos praceres múltiples e do frenesí das alternancias (REGUEIRO, 1998, p. 52)

Neste mesmo poema são observadas características referentes a inserção de uma fantasia erótica a partir da inclusão de uma terceira pessoa no ato sexual. A apresentação desse instinto exclusivamente humano é definida como "sexualidade socializada e transfigurada pela imaginação e vontade dos homens" (PAZ, 1994, p. 16).

O poema inicia o título com apenas uma palavra e termina com quatro, eleva-se gradativamente verso a verso, fazendo uma perfeita alusão ao acréscimo de corpos. Além disso, a locução adverbial do primeiro verso faz uma analogia ao rompimento da rotina, como se "às vezes" só conseguiríamos a plena satisfação, através da figura de um terceiro elemento. O poema possui uma única estrofe, três versos e não tem rima. Porém, é possível perceber a musicalidade apenas através da união dos corpos, como se movimentassem de acordo com uma sinfonia, em um ritmo perfeitamente harmônico. Em relação com esta pluralidade, convém lembrar que para Paz (1994) o protagonista do ato erótico é:

O sexo ou, mais exatamente os sexos. O plural é obrigatório porque, incluindo os chamados prazeres solitários, o desejo sexual inventa sempre um parceiro imaginário... ou muitos (PAZ, 1994, p. 16).

"Núcleo" desenvolve harmoniosamente o ato amoroso entre os participantes. Novamente apresenta um terceiro elemento e, analogamente, representa: o início, o amante à procura de realizar seus desejos; o meio, o 
encontro entre o amante e as amadas e suas respectivas alternâncias; e o ápice, destinado ao próprio encontro erótico. Paz indica que o erotismo é "antes de tudo e sobretudo sede de outridade" (PAZ, 1994, p.20). Essa viagem que percorre os labirintos do corpo, enfrentando a "grande corrida da vida", celebra toda a trajetória em busca do "grande alvo": O "Núcleo", como o ápice do amor, unificação dos corpos, celebração da vida.

"Graças" faz referência ao mito grego do "pomo de ouro": Zeus resolve celebrar o casamento entre Peleu e Tétis e convida outros deuses a participarem, exceto Éris, conhecida como a deusa da discórdia, temendo que esta pudesse causar algum problema. Esta, enfurecida por não ter sido convidada, envia uma maça de ouro retirada de sua própria macieira com a frase, "para a deusa mais bela", o que gera um desentendimento entre Hera, Atena e Afrodite. Zeus, sentindo-se incapaz de avaliar a mais bela, escolhe a um mortal considerado por ele o mais justo, Páris. Este escolhe a oferta de Afrodite e, conforme sabemos, esta decisão ocasionou a Guerra de Tróia, retratada no poema épico Ilíada, de Homero.

A posição do eu lírico se colocando na situação de Zeus, sentindo-se incapaz de escolher a mais bela, ou melhor, evitando escolhê-la, assemelha-se a temática erótica vista em outros poemas, pois ao decidir pelo corpo mais belo, colocar-se-ia em uma condição de parcialidade e a escolha não é realizada a partir da exclusividade, mas sempre pela estética da mais bela. $\mathrm{O}$ erotismo neste poema se desenvolve como uma escala, pois a procura do amante pelo corpo mais belo age como "um impulso vital que ascende, degrau por degrau, até a contemplação do bem supremo" (PAZ, 1998, p. 24). Na obra O Banquete de Platão vemos como esta ideia de ascensão se desenvolve:

quando jovem por dirigir-se aos belos corpos, e em primeiro lugar, se corretamente o dirige o seu dirigente, deve ele amar um só corpo e então 
gerar belos discursos; depois deve ele compreender que a beleza em qualquer corpo é irmã da que está em qualquer outro, e que, se deve procurar o belo na forma, muita tolice seria não considerar uma só e a mesma a beleza em todos os corpos; e depois de entender isso, deve ele fazer-se amante de todos os belos corpos e largar esse amor violento de um só, após desprezá-lo e considerá-lo mesquinho (PLATÃO, 1991, p. 44).

O erotismo nos três poemas se desenvolve como um ritmo: o convite, o encontro e o descobrimento. Estes três pontos cumprem o papel caprichoso ditado pelo mar do erotismo e confirmam aquilo que todos os homens e mulheres tiveram em algum momento e "é a nossa ração de paraíso" (PAZ, 1994, p. 28).

\title{
2 COMPROMISSO UTÓPICO LIBERTÁRIO
}

Claudio Rodríguez Fer defende a livre escolha e a independência feminina, fato que dialoga com a visão de Paz, que afirma que "não há amor sem liberdade feminina" (PAZ, 1996, p. 66). Um poema que aclara essa ideia está na homenagem feita a "Camille Claudel":

\author{
Hoje, cintura a cintura \\ éramos uma valsa: \\ a valsa, vós, eu, \\ Camille Claudel
}

Este poema define outra característica que está intimamente relacionada a trajetória de Claudio Rodríguez Fer: seu compromisso integrador pela liberdade, a justiça e a paz no mundo. Através destes versos, o poeta presta uma homenagem a escultora Camille $\mathrm{Claudel}^{4}$, àquela que perceptivelmente

\footnotetext{
${ }^{4}$ Camille Claudel, cujo verdadeiro nome era Camille Athanaise Cécile Cerveaux Prosper, nasceu em 8 de dezembro de 1864 e faleceu no 19 de outubro de 1943, irmã mais velha do conhecido poeta e diplomata Paul Claudel, foi uma escultura do impressionismo francês. Desde a infância, ela já demonstrava interesse pela arte e, pode aprimorá-la na Academia Colarossi, único lugar na época que aceitava estudantes mulheres, tendo sido aluna de Alfred Boucher.
} 
esteve à frente de seu tempo, tendo lutado contra as repressões sociais que impediam mulheres de estudar ou seguir determinadas carreiras, às injustiças familiares que a obrigaram a viver circunstancias indesejáveis, e também a escolha de viver o amor em sua forma mais sublime. Lembre-se que para Octavio Paz “todo amor, incluindo o mais feliz, é trágico” (PAZ, 1994, p. 101).

O relacionamento vivido entre Camille Claudel e Auguste Rodin unia genialidade, talento, afetividade, mas também tragédia, pois a escolha de viver livremente esse amor, levou a personagem deste poema à loucura, pois o amor é "um sentimento estranho que é simultaneamente uma atração fatal e uma livre escolha" (PAZ, 1994, p. 95). Paz afirma que “a atração que experimentam os amantes é involuntária, nasce de um magnetismo secreto e todo-poderoso; ao mesmo tempo, é uma escolha" (PAZ, 1994, p. 3).

Embora conheçamos a respeito desse paradoxo vivido por ela, o poema nos aporta algumas características que permitem uma readequação contemporânea a supracitada história de amor. $\mathrm{O}$ poeta não menciona a respeito de exclusividade, o que mantém os elementos baseados em um possível relacionamento aberto. Porém, através do advérbio hoje, ele convida a reviver o ápice do amor vivido pelos apaixonados, cuja transgressão permita encontrar a sua metade perdida por meio do outro corpo, conforme o mito do andrógino. Para Paz, "somos seres incompletos e o desejo amoroso é a perpétua sede de incompletude" (PAZ, 1994, p. 41). A combinação das palavras "cintura a cintura" tem uma conotação sexual, permitindo a interpretação da união entre os corpos, indicando o início e/ou apogeu do prazer, cujos movimentos estão

\footnotetext{
Através deste, ela conhece Auguste Rodin, tornando-se rapidamente seu confidente, sua inspiração e seu amante. Embora Rodin possuísse um relacionamento com Rose Beuret, com quem relutava em terminar, seu envolvimento com Camille era de conhecimento de todos, inclusive sendo reprovado pela família dela. Em 1892, após sofrer um aborto, ela resolve pôr um fim em seu envolvimento íntimo com Rodin e passa a sofrer as consequências do rompimento. Considerada pela grande massa jornalista da época um gênio enclausurado pela própria família, Camille morre em 1943 no manicômio de Montifavet, sendo enterrada em uma vala comum.
} 
em perfeita sintonia ou completude, igual uma valsa ou até mesmo ao ritmo dessa melodia. Por fim, o eu lírico se coloca na posição central e inclina seu convite a vivenciar esse amor carnal, esse prazer sublime dedicado apenas a escolha de realizar o encontro em seu máximo descobrimento. O ápice e as emoções cognoscitivas apresentados no poema se realizam em "Explosão":

\author{
Múltiplas \\ na explosão \\ que detonamos \\ unânimes.
}

\title{
3 À PROCURA DO OBJETO
}

O amante, o protagonista poemático, coloca-se à disposição em oferecer seu amor incomensurável, livre, transcendente - assim como a história de Eros \& Psiquê ${ }^{5}$-, oferecendo a amada todo o seu ser e convidando-a a desfrutar dessa união utópica e celestial, a fim de experimentar aquilo que não foi descoberto. Percebemos à busca pela presença da amada em poemas como "Iniciativa", "Vulvas" e "Flores":

\author{
Iniciativa \\ Descobrir o desejo \\ na imprevista iniciativa \\ de beijar uma boca \\ em busca de ternura.
}

\footnotetext{
${ }^{5}$ Lenda da mitologia grega que narra a paixão transcendental entre o deus Eros e a mortal Psiquê. Filha de um rei e a mais nova entre três irmãs, a jovem Psiquê possuía uma beleza que lhe rendia vários admiradores e alguns desafetos, citando como principal a deusa Afrodite. Esta, enciumada por ser a própria deusa da beleza, ordena que seu filho Eros faça com que a jovem se apaixone por alguém, porém este se encanta com a beleza de Psiquê e acaba apaixonando-se perdidamente por ela. Para que esse amor se torne transcendente e permissível aos olhos dos deuses, a jovem precisa cumprir algumas tarefas impostas por Afrodite, cuja última lhe será mortal. Seu sono eterno será retirado pelo deus Eros, que conseguirá junto a sua mãe a permissão necessária para viver esse amor eterno e cosmogônico.
} 


\section{Vulvas}

As vulvas sorriem

sempre entre si

E nenhuma língua

lhes resulta estrangeira.

\section{Flores}

Sépalas, pétalas, húmidas, juntas.

Toda essa união, descobrimento e perfeita sintonia dialogam com o que Olga Novo justifica como "corpos que se aman ata o lique na exploración do sentimento, desde a paixón á tenrura, desde a amizade ó amor, desde a atracción sensual à intelectual" (NOVO, 2008, p. 22). A busca pela exploração máxima do sentimento oferece ao amante a possibilidade de alternar com a amada o ato de dar e receber prazer, elevando-os como partículas a outro território. Estes aspectos representam para Novo como o "amor que arrebata, xeo abrasador e lume xeado que transporta os amantes, fai do poeta esencia do amor, e nel tamén, suxeito activo e passivo a um mesmo tempo: e son o amor o amante e mais o amado" (NOVO, 2008, p. 25).

"Vulvas" sintetiza o encontro entre os amados, revela-se sublime como “o altar e lugar sagrado tántrico onde se realiza o sacrifício, o rito do encanto máxico do amante" (NOVO, 2008, p. 35). Para Saturnino Valladares, este encontro revela “o sorriso e o riso, o sabor e a negação da estrangeira no encontro amoroso. Uma Babel antibíblica" (VALLADARES, 2014, p. 4).

Em "Flores" percebemos a definição completa de uma vulva, suas características, seu formato, seu erotismo e seu transcendentalismo, pois "a vulva é um aparente caos xenital que contén a mesma estrutura do universo" (NOVO, 2008, p. 37). 
O convite a esse paraíso erótico, cujo padrão subverte as normas tradicionais, é o que define a poética de Claudio Rodríguez Fer. Em “Cerracín”, árvores centenárias que ajudam o poeta a descobrir em seu interior a mulher que há em Galicia e seu glorioso esplendor, pois “a beleza desta natureza celta suscita no autor um vínculo intenso e original que o conecta com uma época anterior a pré-história" (VALLADARES, 2021, p. 7):

\author{
Somente \\ tenho uma vida \\ para dar-vos: \\ mas darei-vos-la \\ arvoreamente \\ milenária.
}

\title{
CONSIDERAÇÕES FINAIS
}

Esta breve análise permitiu apresentar de forma parcial a parte intitulada "Somente a apoteose" da obra Uma temporada no paraíso. Através de seus micropoemas, Claudio Rodríguez Fer mostra seu belo repertório artístico, sua temática intelectual e sua perspectiva vitalista que o tornaram pioneiro do erotismo na literatura galega. Com seus poemas em língua galega, perfila seus versos com a ideia de que "a vida é mais formosa no paraíso" (VALLADARES, 2014, p. 3).

Este Eros libertário identifica sua poesia com a sua vida, acolhe o diverso, sem exclusões, e transforma a terra em um paraíso carnal, onde a união entre o distinto pode converter-se em uma apoteose. As viagens propostas pelo poeta percorrem toda uma paisagem celta que o conectam a sua origem, elevam-se também a um universo cosmogônico que nos transporta a um nomadismo ancestral e celebra a vida desde sua origem celular, onde o "Núcleo" aguarda de forma ansiosa a chegada do ganhador da "grande corrida da vida". Portanto, "Somente a apoteose" se apresenta como "um ciclo de indagação estética e 
sensual em relação a experimentação sexual" que conduz a "um novo princípio, feminista e libertário" (NOVO, 2010, p. 15).

Neste trabalho pudemos analisar a temática erótica e o compromisso social, através de alguns poemas significativos. Além disso, foram utilizados autores que pudessem dar o respaldo necessário para a criação de um embasamento teórico, tais como Octavio Paz (1994), Saturnino Valladares (2014; 2021), Olga Novo (1996; 2008; 2010) e Natalia Regueiro (1998).

\section{REFERÊNCIAS}

NOVO, Olga. Claudio Rodríguez Fer. Unha traxectoria em anos e páxinas. In: RODRÍGUEZ FER, Claudio. Unha tempada no paraíso. Santiago de Compostela: Toxosoutos, 2010.

NOVO, Olga. O Lume vital de Claudio Rodríguez Fer: Erotismo, coñecemento e utopias. Santiago de Compostela: Follas Novas, 2008.

NOVO, Olga. Por un vocabulário galego do sexo: A terminoloxía erótica de Claudio Rodríguez Fer. Santiago de Compostela: Positivas, 1996.

PAZ, Octavio. A dupla chama: amor e erotismo. São Paulo: Siciliano, 1994.

PLATÃO. Banquete, Fédon, Sofista e Político. Tradução por José Cavalcante de Souza, Jorge Paleikat e João Cruz Costa. São Paulo: Nova Cultural, 1991.

REGUEIRO, Natalia. Os mundos de Claudio Rodríguez Fer. Lugo: do Castro, 1998.

RODRÍGUEZ FER, Claudio. Uma temporada no paraíso. Tradução e apresentação de Saturnino Valladares. Manaus: Valer, 2019.

VALLADARES, Saturnino. La Galicia erótica de Claudio Rodríguez Fer. Entreletras, Maturín, n. 9, p. 125-129, jan./jun. 2021.

VALLADARES, Saturnino. Uma aproximação a Unha tempada no paraíso, de Claudio Rodríguez Fer. Revista electrónica de los hispanistas de Brasil, Alcalá, v. 15, n. 59, p. 1-10, 2014.

Nota do editor:

Artigo submetido para avaliação em: 30 de março de 2021.

Aprovado em sistema duplo cego em: 10 de julho de 2021. 